\title{
Interpretación Narrativa del Amor en los Tiempos del Cólera
}

\author{
Luis Quintana Tejera \\ Facultad de Humanidades-UAEM
}

Resumen: El presente artículo tiene como finalidad llevar a cabo una crítica de diferentes temas tratados por el narrador en la novela El amor en los tiempos del cólera. La contextualización de la muerte desde dos ángulos diferentes nos permitirá profundizar en relaciones literarias trascendentales. Asímismo el hecho de revisar el sentido de la asociación de conceptos, los amores contrariados y la comicidad como un alivio necesario para la tragedia, nos ubica en el terreno siempre propicio de la reflexión filosófica.

Abstract: This essay is a reflect on different subject matter brings by the novel author's "El amor en los tiempos de cólera." By context death from two different points of view the author let us to enter to transcendent literary relations.

\section{Introducción}

H

emos escogido para la contextualización del presente análisis la novela del colombiano García Márquez titulada El amor en los tiempos del cólera, y nos permitimos inicialmente efectuar una breve comparación con Cien años de soledad del mismo autor.

En este sentido coincidimos con Jorge Amado (1991: 1), quien señala: "Gabo escribió dos de las novelas más importantes de la ficción contemporánea: Cien años de soledad y El amor en los tiempos del cólera.

Nos centraremos en el análisis de varios temas que consideramos relevantes en el contexto de la novela en cuestión; es decir que a través de la contextualización de la muerte -la de Jeremiah y la de Juvenal Urbino-, el sentido de la asociación, los amores contrariados y la comicidad como un paliativo necesario para la tragedia, aludiremos a diversos aspectos que se enmarcan en reflexiones literarias de distinto alcance. 


\section{Planteamiento inicial}

Los comienzos en las novelas de G.G.M. no sólo son importantes, sino que también resultan reveladores -en el marco de un eventual movimiento temporal-, a través del cual se nos saca del presente del relato para permitir que se adueñe de nosotros una especie de interrogante, de curiosidad particular, relativa a la anécdota que se nos pretende transmitir.

En Cien años de soledad el narrador empieza diciendo:

Muchos años después, frente al pelotón de fusilamiento, el coronel Aureliano Buendía había de recordar aquella tarde remota en que su padre lo llevó a conocer el hielo... (García Márquez, 1990).

Nos hallamos ante un acontecimiento trascendente como puede ser el de un hombre enfrentado a la muerte. Es aquí donde esta forma de morir se nos antoja como realmente absurda: soportar que otros decidan que ya no podemos pertener a esta tierra y llegar a entender las palabras del coronel Aureliano Buendía: "Tanto joderse uno (...) Tanto joderse para que lo maten a uno seis maricas sin poder hacer nada" (García Márquez, 1990: 138) es asumir el carácter contundente que los hechos de vida muchas veces conllevan; es incorporar la noción de impotencia que domina al personaje en el que va a ser -aparentemente- el último momento de su existencia.

La proyección de los acontecimientos se ofrece mediante un extraño manejo temporal en el cual lo ya ocurrido se mezcla con lo que está por acontecer: una tarde cualquiera; el interminable coronel frente al pelotón, del cual escapará como de tantos otros acontecimientos límites en su existencia, que transcurren sin herirlo a pesar de la violencia que conllevan, y un recuerdo que tiene mucho de proyección individual si nos fijamos en la enorme carga emocional que implica.

En El amor en los tiempos del cólera se dice en el inicio:

Era inevitable: el olor de las almendras amargas le recordaba siempre el destino de los amores contrariados. El doctor Juvenal Urbino lo percibió desde que entró en la casa todavía en penumbras, adonde había acudido de urgencia a ocuparse de un caso que para él había dejado de ser urgente desde hacía muchos años (García Márquez, 1990: 9).

Las semejanzas no sólo son conceptuales mediante la reiteración del leit motiv de los amores contrariados asociados al olor de las almendras amargas, sino también en la forma y claves en que se ofrecen los hechos: 
1. Un acontecimiento trascendente: el suicidio del amigo.

2. El nombre del personaje que -junto con los otros-teje la trama de los sucesos.

3. De nuevo, el manejo temporal en donde el narrador empieza a contar una historia y para ello se apoya en sucesos anteriores, al mismo tiempo que anuncia lo que vendrá. Esas implacables analepsis contrastadas con las prolepsis, configuran el notable ir $\mathrm{y}$ venir del narrador a través del tiempo del relato.

La voz que cuenta los hechos se expresa como si estuviera - al mismo tiempo - reflexionando sobre ellos: "Era inevitable". Quizás no se haya observado con la suficiente profundidad el carácter fatalista de muchas de las afirmaciones del narrador de esta novela y de otras del mismo autor. Oímos en múltiples ocasiones - en boca del hombre contemporáneo - algo parecido; se nos ocurre pensar que este mismo individuo, a pesar de pertenecer al mundo de la tecnología apabullante, en variadas oportunidades se deja convencer por aspectos nada científicos. Es verdad que el ser humano no puede prevenir los hechos, pero sí puede prepararse para vivir épocas de crisis profundas y llegar a concluir que nada es inevitable y que todo puede ser previsible. Ahora bien, en el universo macondiano de García Márquez sí existe la fuerza fatal del amor y, más aún, de los amores contrariados. Y decimos macondianos, porque aunque el autor anunció que había concluido el ciclo de Cien años de soledad, la primera incorporación conceptual de El amor en los tiempos del cólera, posee ese carácter fatal e ineludible que ya habíamos encontrado en la novela de 1967. Aunado a ello reaparece también aquel bello símbolo de las almendras amargas, que aquí se descubre en el olor peculiar del cianuro de oro.

\section{EI valor de la asociación}

Hablemos ahora del valor de la asociación y de la resonancia que este concepto ha tenido en algunas manifestaciones narrativas de fines del siglo XIX y principios del XX. Podemos partir de la premisa siguiente: asociar es sentir. A medida que el hombre va viviendo parece como que contamina las cosas con su presencia. Un río que hemos observado detenidamente cuando teníamos en nuestros brazos a la mujer amada -que hoy ya no está con nosotros-, regresa a nuestra conciencia en el momento menos pensado, ya sea porque hemos visto aquella imagen 
del río representada arbitrariamente, o porque algo la trajo de pronto y no podemos así dejar de sentir.

Cuando en Eugenia Grandet, de Honoré de Balzac, Carlos Grandet recibe la noticia de la muerte de su padre en el jardín del avaro, el paisaje de ese jardín quedará grabado para siempre en la mente del joven en directa asociación con la noticia que recibe en este instante (Balzac, 1990). El genio de Balzac ha incursionado así en el justo carácter de esta relación entre los elementos, relación que pertenece al dominio de lo inconsciente y que resulta muy difícil de controlar en el ser humano.

De la misma forma en A la búsqueda del tiempo perdido de Marcel Proust y más específicamente en Por el camino de Swann, se plantea un caso semejante en el terreno de la asociación aquí estudiada. Señala al respecto el narrador protagonista:

Así ocurre con nuestro trabajo pasado. Es trabajo perdido el que intentemos evocarlo, son inútiles todos los esfuerzos de nuestra inteligencia. Está oculto fuera de su dominio y de su alcance, en algún objeto material -en la sensación que nos produciría ese objeto material- que no sospechamos. Este objeto depende del azar que lo encontremos antes de morir, o que no lo encontremos (Proust, 1985: 71).

Alude así al dominio de lo inconsciente y, pocos renglones más adelante, lo fundamenta con un hecho que le aconteció a este mismo narrador personaje. Dice al respecto:

Hacía y a muchos años que, en Combray, todo lo que no era el teatro y el drama de acostarme, no existía y a para mí, cuando un día de invierno, al volver a casa, mi madre, viendo que tenía yo frío, me propuso que tomase, en contra de mi costumbre, un poco de té. Me negué al principio y, no sé por qué, cambié de parecer. Envió a buscar uno de esos pasteles pequeños y gruesos llamados magdalenas(...) Llevé a mis labios una cucharada de té en la que había mojado un trozo de magdalena. Pero en el instante mismo en que el sorbo mezclado con las migas del pastel tocó mi paladar, me estremecí, atento a algo extraordinario que ocurría dentro de mí. Habíame invadido un placer delicioso, aislado, sin la noción de su causa. Me habían hecho de nuevo las vicisitudes de la vida indiferente, sus desastres inofensivos, su brevedad ilusoria, de la misma manera que actúa el amor, colmándome de una esencia preciada: o más bien esta esencia no estaba en mí, era yo mismo. Había cesado de sentirme mediocre, limitado, mortal. ¿De dónde podía provenir aquella misteriosa alegría? Sentía que iba ligada al sabor del té y del pastel. Pero que lo superaba infinitamente, que no debía ser de la misma naturaleza. (...) Es evidente que la verdad que busco no está en él, sino en mí. La ha despertado, pero no la conoce (Proust, 1985: 71-72). 
Queda documentado, a través de la larga cita anterior, un curioso ejemplo -repetido hasta el cansancio por muchos estudiosos de Proust-, de una forma de memoria que no es precisamente voluntaria, sino que posee un carácter involuntario, que no puede ser evocado, sólo llega a nosotros en el momento menos pensado.

Tres párrafos más adelante el narrador nos cuenta cómo se produjo de pronto la luz del recuerdo:

Ese sabor era el del trocito de magdalena que el domingo por la mañana en Combray (porque ese día no salía yo antes de la hora de misa), cuando iba a darle los buenos días a su alcoba, mi tía Leoncia me ofrecía después de haberlo mojado en su infusión de té o de tila. La visión de la pequeña magdalena no me habia recordado nada antes de que la hubiese probado; quizás porque, habiéndolas visto a menudo posteriormente, sobre los anaqueles de los pasteleros, sin comerlas, su imagen había abandonado aquellos dias de Combray para unirse a otros más recientes; quizás porque, de esos recuerdos apartados tanto tiempo de la memoria, no sobrevivía nada (Proust, 1985: 73).

Como es dado inferir a través de los dos ejemplos y de la misma situación considerada en la novela del colombiano, las sensaciones que entran en acción son de diferente naturaleza; en Balzac, predomina lo visual, la fijación - por medio de la vista del personaje -, de todo aquel paisaje de Saumur; en Proust, la sensación da inicio en lo gustativo, y de ahí permite el gran salto en el espacio temporal; en Márquez, esta misma sensación es de carácter olfativa: el olor de las almendras recuerda otro olor.

Mediante los datos sinestésicos anteriormente reseñados se llega a la asociación que bien puede tener origen en otras sensaciones que estén muy arraigadas en el sujeto que padece los acontecimientos:

- La muerte de Jeremiah de Saint-Amour

- El proceder de Juvenal

Ahora bien, los referentes que tienen como punto de coincidencia la muerte, son absolutamente frecuentes en García Márquez y en el caso específico de esta novela resultan contrastantes con hechos tales como los que aluden al amor realizado y los que se refieren a situaciones jocosas. Cuando el narrador dice que el doctor lo percibió, alude a una forma de conocimiento tan compleja como es la intuición (Abbagnano, 1989: 699). Le bastó al personaje ingresar a ese sitio para comprender en toda su trascendencia, en toda su condición de destino irreversible, lo que estaba sucediendo. Considerado estrictamente, éste no es un 
suicidio por amor, al menos no lo es por amor a la pareja, puesto que la mujer amada de Jeremiah, su pareja, estuvo con él esa noche y lo dejó solo únicamente porque ésta era la voluntad del inválido. Ahora bien, esa decisión implacable del antillano que lo conduce a la muerte por no atreverse a soportar las vicisitudes de la vejez, representa otra curiosa forma de amor, el amor a la muerte que se ofrece así como la mejor curación para la enfermedad de la vida. Esto último corresponde conectarlo con lo que también dice el narrador renglones más adelante, cuando aclara que el personaje se "había puesto a salvo de los tormentos de la memoria con un sahumerio de cianuro de oro." El lenguaje figurado juega aquí un papel muy importante; esa idea de ponerse a salvo de los tormentos de la memoria mediante el suicidio, es una curiosa metáfora en donde la voz que habla relaciona claramente el hecho de vivir con el hecho de sufrir. Dicho de otra manera, el hombre va muriendo en cada acto de vida, se va despojando de su condición vital a medida que envejece, para descubrirse un día frente a frente con la muerte y llegar a aceptarla como una solución para esa triste enfermedad que es la existencia humana. Muchos lectores pueden pensar que es ésta una forma pesimista de interpretar la vida; mas -en el contexto existencialista ateo-, esta visión es implacable, pero auténtica. Si decía Platón comentando a Sócrates que "aprender es recordar", aquí recordar es sufrir. Cada acto de pensamiento conduce al individuo a una dolorosa introspección de la cual le cuesta muchos sacrificios salir. Jeremiah decidió su muerte en un acto libre de su voluntad; quiso dejarlo todo, porque ya no le encontraba sentido a las cosas, o por lo menos no le hallaba la significación que él deseaba.

A este respecto señala Grinor Rojo:

Ésta es la variable que Jeremiah de Saint-Amour introduce en los sucesos del primer plano en $\mathrm{El}$ amor en los tiempos del cólera y de lo que colegimos que él no pertenece a la misma raza de personajes a la que pertenecen Juvenal Urbino y Florentino Ariza. Su solución al enigma de la vejez y de la muerte no es la de ellos. Si él muere para no envejecer, los otros envejecen para no morir. El suicidio de Saint-Amour, que contiene una denuncia del envejecimiento, de sus racionalizaciones hábiles, de sus mentiras astutas, contiene también una propuesta ardientemente desencantada para desentenderse del desafio del tiempo (Grinor Rojo: 1991: 365).

Además, en muchas ocasiones, las diversas conceptualizaciones del universo no coinciden. Esto lo observamos cuando el anciano doctor se detiene en la contemplación del cadáver del amigo y comenta el narrador: 
El doctor Juvenal Urbino lo contempló un instante con el corazón adolorido como muy pocas veces en los largos años de su contienda estéril contra la muerte.

-Pendejo-le dijo-. Ya lo peor había pasado. (El Amor en los tiempos del cólera (EATC): 10)

He ahí dos cosmovisiones diferentes. La de quien se ha quitado la vida invadido por ese patético terror a seguir enfrentando cada momento; y la de quien -al evaluar la decisión ajena-, deja escapar esa palabra altisonante. Y, severa ironía del destino, quien tal cosa sostiene morirá pocas horas después al intentar bajar de un árbol al curioso loro políglota. Tenemos así dos decesos sucesivos, quizá dos formas de dejar de ser igualmente estúpidas.

Ahora bien, el hecho de ponernos de acuerdo con la inutilidad de estas muertes, no significa de modo alguno invalidar al suicidio como una posibilidad de liberación individual; todas las consideraciones que puedan efectuarse en torno al derecho que tenga el hombre de quitarse la vida, aparecerán permeadas de subjetividad. Hay quien por sistema doctrinal condena tal actitud, y hay también quienes la resaltan como acto heroico, y otros que lo denominan cobardía. Para nosotros es tan sólo un hecho más que aleja al hombre de la posibilidad de llevar a cabo muchas realizaciones y que -quizá por esta misma razón-, los que se matan aparecen como víctimas de la tortura intelectual de otros individuos que los rodean, o tal vez resulten tan sólo pobres personas que desean huir de la deplorable soledad que tarde o temprano termina atrapando al hombre.

El anciano doctor había protegido en todo momento a Jeremiah de Saint Amour y ahora cumple con el viejo amigo preparando todo lo necesario para los trámites mortuorios:

Ordenó decir a los periódicos que el fotógrafo había muerto de muerte natural, aunque pensaba que la noticia no les interesaba de ningún modo. Dijo: "Si es necesario, yo hablaré con el gobernador". El comisario, un empleado serio y humilde, sabia que el rigor cívico del maestro exasperaba hasta a sus amigos más próximos, y estaba sorprendido por la facilidad con que saltaba por encima de los trámites legales para apresurar el entierro (EATC: 12).

El doctor Juvenal procede de una manera arbitraria y lo hace para proteger la memoria del amigo. Al saltar los trámites legales demuestra su autoridad en el pueblo, autoridad basada precisamente en la función médica y en la costumbre de codearse con la muerte.

La obra de Márquez refleja así circunstancias cotidianas en el contexto de una Latinoamérica que aún no había entrado en la 
modernidad. La figura y la presencia del médico infundían un profundo respeto en la gente. Todos sabían que en cualquier momento podían precisar de él y por eso, precisamente por eso, escuchaban su voz como si se tratara de la única opinión válida. Además de todo lo anterior, Juvenal poseía un "ojo clínico", un carisma tan particular que podía adivinar de qué enfermedad se trataba con sólo ver al paciente.

Interesaría resaltar a esta altura del análisis la capacidad tan especial del narrador para mantenerse fiel a un sinnúmero de ideas defendidas y sustentadas por sus personajes, así como también el profundo sentido de la comicidad y de la fundamentación dada al aspecto risueño, en momentos en los cuales el lector ni siquiera piensa que tal situación pueda imponerse. Las consideraciones que siguen aluden a lo anterior. Más adelante en el desarrollo del trabajo, analizaremos las situaciones cómicas con fundamento en el pasaje hiperbólico en que se habla de aquel loro de Paramaribo que se había transformado en la única presencia animal-irracional de la casa. Vayamos al primer aspecto.

Juvenal no accede a hablar con el arzobispo por viejas rencillas entre ambos; no quiere solicitar la autorización para que Jeremiah de Saint-Amour sea sepultado en tierra sagrada. Al no pedir esto, parece aceptar tácitamente la condición de suicida de su amigo, pero al mismo tiempo responde de forma tajante cuando el comisario señala que el paralítico era un santo: "Algo todavía más raro (...) un santo ateo. Pero esos son asuntos de Dios" (EATC: 12) dice el personaje. Esta respuesta se impone como esas máximas incluidas en la obra del colombiano, las cuales valen más por el impacto que producen que por la verdad que conllevan al utilizarse. Sólo mediante el oxímoron "santo ateo" podemos incorporar una noción tan curiosamente contradictoria, pero reafirmadora en su propia contradicción, de una de las verdades más intensas que la literatura pueda haber llegado a sostener. La verdad no es patrimonio de ninguna tendencia, se puede llegar a creer en Dios desde una perspectiva curiosamente escéptica; se puede amar a Dios desde el nihilismo enajenante de un corazón que no quiere hacer suyos esos paradigmas que muchos defienden como condición absoluta. Esa misma Iglesia que le niega al suicida la posibilidad de tierra santa para que descansen sus restos, es la que se atreve a sostener la existencia de un Dios tan implacable del que sólo encontramos parangón en viejos textos de la mitología griega permeados de decadente antropomorfismo, y en muchos momentos del implacable Antiguo 
Testamento de la Biblia. La postura del narrador es altamente crítica en este momento. Defiende -más allá de doctrinas y tendencias-, la libertad del hombre; libertad que inclusive lo puede llevar a la autodestrucción, pero que no por esto debe condenarse.

"Pero esos son asuntos de Dios". Se trata de aproximarnos a una libre interpretación teísta, en la cual las religiones deben dejar su lugar a la reflexión serena de la conciencia. El dios garciamarquiano no parece responder a imperativos categóricos, sino que por el contrario acompaña al hombre pecador; lo comprende, lo ayuda, lo apoya. Desde los infinitos experimentos de José Arcadio en Cien años de soledad para tratar de obtener un daguerrotipo de Dios, desde ese intento imposible por reproducir lo irreproducible, notamos la latente preocupación en el mundo narrativo del colombiano, por acceder a Dios, por integrarlo, por lograr quizás la simple aprehensión del concepto divino. Es aquí en donde se enfrentan las tendencias racionales con la metafísica. Inclusive la propia racionalidad de la Iglesia para interpretar los designios de Dios se opone a la propuesta narrativa que estamos analizando, propuesta que resulta fundamentada -precisamente-, en el hecho de llegar a incorporar correctamente cuáles son o pueden llegar a ser los "asuntos de Dios". Hay algo que continúa siendo auténtico, vigente, real en su propia contradicción: Dios no puede castigar al hombre gratuitamente, Dios no es negación y fuerza, sino realización y vida.

\section{Los amores contrariados}

El doctor Juvenal -después de cumplir con los trámites que le correspondían en su carácter de médico forense-, se aleja del lugar para trasladarse a la casa de la amante del fallecido Jeremiah. Al llegar se encuentra de pronto en un ambiente tranquilamente fúnebre. Comprende en seguida que su visita es inútil si la medimos en relación con la noticia que viene a comunicar. La amante ya lo sabe todo. Sus palabras son terminantes: "Esta es su casa, doctor-dijo-. No lo esperaba tan pronto" (EATC: 20).

El narrador se mete de lleno -en forma inmediata-, en una hermosa analepsis en la cual se encarga de describir y recrear los momentos de extraña felicidad vividos en el pasado por los amantes clandestinos. Esta analepsis es muy extensa como para transcribirla en su totalidad, por ello dividiremos los planteamientos contenidos en la misma en varios momentos. 
En primer lugar dice la voz que relata los hechos:

Así era. Ella lo había acompañado hasta muy pocas horas antes de la muerte, como lo había acompañado durante media vida con una devoción y una ternura sumisa que se parecian demasiado al amor, y sin que nadie lo supiera en esta soñolienta capital de provincia donde eran de dominio público hasta los secretos de estado (EATC: 21).

Es ésta una manera de narrar muy curiosa que parece retroalimentarse en su propio fluir. Al empezar a contar esta historia de amor, la voz que relata se hace cargo de la profunda significación que la misma reviste. Muchas nociones se imponen aquí, tales como la compañía que anula la soledad, la fidelidad hasta la muerte, la devoción por el ser querido, la ternura sumisa, la devoción y la ternura que si no eran el amor se parecían demasiado a ese concepto, la clandestinidad sin sentido, el ocultamiento en un lugar donde nada se podía encubrir -ni siquiera los secretos de estado-. En fin, todo esto da la imagen de una mutua entrega, de un vivir el uno para el otro en ese espacio sumiso del amor. Tiempo y espacio se descubren también íntimamente compenetrados en la extraña residencia del inválido de guerra.Y también los espacios se ofrecen de una manera circular en donde se van implicando de mayor a menor: el amplio ambiente continental, el cerrado recinto de la provincia, el estrecho sitio de la casa.

Al enfocar el tema de los amores contrariados y el tema del amor en sí mismo, se impone como una condición necesaria hablar de esa relación tan peculiar entre los seres humanos que hemos denominado amor. En esta novela la voz que cuenta no sabe o no quiere definir el concepto en cuestión. Observamos cómo esa devoción y esa ternura son lo más aproximado al amor, y así se ofrece en este contexto. He aquí la manera más elegante de evitar -si no la definición-, al menos una caracterización más o menos comprometida acerca de este asunto.

Páginas más adelante Juvenal contestará al reproche de Fermina Daza relativo a que no ha sido feliz en la relación matrimonial, que lo más importante de la vida es la estabilidad, y él se la ha dado, precisamente. He ahí dos polos de relación que se implican y tienen mucho que ver con el amor: felicidad y estabilidad. El amor necesita de ambos aunque no se identifique plenamente con ninguno de los dos.

Ahora bien, hablemos de las almendras amargas, detengámonos un momento en el gran tema de los amores contrariados. ¿Qué fue lo que 
percibió Juvenal Urbino al ingresar en la casa del suicida? Digamos que llegaron a él mensajes de siglos enteros vividos en medio de la contrariedad y el desengaño. El amor es uno de los demonios que aprisionan al hombre, que lo hacen sufrir intensamente, que se apoderan de su alma atormentada y que sólo lo dejan en paz cuando el tiempo les permite reflexionar acerca de la invalidez del sacrificio (García Márquez, 1990). Es ésta una posible caracterización acerca del tema, que toma como fundamento la obra mencionada en la cita anterior.

Asimismo, El amor en los tiempos del cólera desarrolla el motivo de la espera más allá de los plazos que cualquier amante pudiera soportar. Florentino y Fermina parecen demostrar que los amores contrariados no existen y que sólo se trata de practicar la paciencia como una virtud complementaria; por supuesto, la paciencia excluye los celos e involucra al hombre con una profunda fe en el porvenir. El amante que espera -como Ariza- no debe desesperar: el tiempo será el gran juez que emitirá su veredicto de manera ineludible y cierta.

De esta forma, tenemos por un lado los amores contrariados que implican una posición narrativa pesimista; y por otro, los amores realizados de la esposa viuda y el amante empedernido de tantas jornadas.

Jeremiah y su mujer representan también amores clandestinos que se antojan como innecesarios. Y por eso al doctor Urbino: "Le costaba trabajo entender que dos adultos libres y sin pasado, al margen de los prejuicios de una sociedad ensimismada, hubieran elegido el azar de los amores prohibidos" (EATC: 21). Ellos parecen practicarlo como un ejercicio de la edad adulta. Insistamos al mismo tiempo que no es de ninguna manera ésta la razón que arrastró al inválido de guerra a su autodestrucción.

La amante viuda se encarga de explicar al anciano médico la razón poderosa que llevó a su hombre a la muerte: "Era su gusto" le dice, implicando con esto el profundo respeto que sentía por aquel hombre, y su firme decisión de acompañarlo hasta donde fuera posible, no más allá.

Y quizás lo que se nos imponga a nosotros -hombres comunes y corrientes que no estamos acostumbrados a los arduos menesteres del heroísmo-, sea una profunda tristeza y desolación cuando leemos: 
Había querido llevarse el perro, pero él lo contempló adormilado junto a las muletas y lo acarició con la punta de los dedos. Dijo: "Lo siento, pero Mister Woodrow Wilson se va conmigo" Le pidió a ella que lo amarrara en la pata del catre mientras él escribía, y ella lo hizo con un nudo falso para que pudiera soltarse. Aquel había sido su único acto de deslealtad y estaba justificado por el deseo de seguir recordando al amo en los ojos invernales de su perro. Pero el doctor Urbino la interrumpió para contarle que el perro no se había soltado. Ella dijo: "Entonces fue porque no quiso". Y se alegró, porque prefería seguir evocando al amante muerto como él se lo había pedido la noche anterior, cuando interrumpió la carta que ya había comenzado y la miró por última vez. -Recuérdame con una rosa- le dijo (EATC: 23).

El tema de la lealtad aparece bosquejado así y hermosamente sintetizado en dos procederes: el del perro y el de la amante. Como si el perro fuese un sumiso amante y como si la amante fuese un perro fiel.

El perro no abandona a su amo aunque tiene la opción de hacerlo. Ese nudo corredizo representa quizás la -digámoslo con un oxímoron-, endeble fortaleza de los lazos que unían al amo y al animal. Ese nudo corredizo es también un símbolo que alude a la relación de Jeremiah y su amante: ella lo deja irse sin reproches, adopta la heroica actitud de la resignación sin atreverse a una rebeldía que hubiera resultado no sólo fuera de lugar, sino también inútil y extremadamente ególatra. Es ésta una manifestación del amor, del demonio del amor, que hace sufrir al hombre y a la mujer más allá de su propia resistencia.

\section{Comicidad de situaciones}

En fin, abandonemos la casa de la amante y acompañemos al doctor en el regreso a su propia casa. Dejemos de lado la tristeza horrible de la muerte y escojamos otro aspecto ya anunciado en el presente texto: la comicidad de situaciones.

La historia del loro de Paramaribo se ofrece como una de esas metadiégesis que sólo García Márquez sabe contar con precisión y ludismo inequívocos.

Estaba en la casa desde hacía más de veinte años, y nadie supo cuántos había vivido antes. Todas las tardes después de la siesta, el doctor Urbino se sentaba con él en la terraza del patio, que era el lugar más fresco de la casa, y habia apelado a los recursos más arduos de su pasión pedagógica, hasta que el loro aprendió a hablar el francés como un académico. Después, por puro vicio de la virtud, le enseñó el acompañamiento de la misa en latín y algunos trozos escogidos del Evangelio según San Mateo, y trató sin fortuna de inculcarle una noción mecánica de las cuatro operaciones aritméticas (EATC: 28). 
Se recrea así un amplio sentido picaresco por parte del narrador en donde prevalece no sólo la hipérbole del loco decir, sino también y fundamentalmente la ironía de la sugerencia precisa, enmascarada detrás de varios procedimientos lingüísticos.

Observamos cómo la capacidad didáctica de Juvenal se pone en juego y logra lo imposible: transformar al loro en un políglota: conocedor del francés, del latín y del griego. La ironía hace su irrupción cuando señala la voz que cuenta los hechos que aprendió francés "como un académico..."

En fin, no todo es triunfo pedagógico en la ardua lucha por instruir al plumífero parlanchín, sino que el doctor fracasa rotundamente cuando pretende enseñarle las cuatro operaciones aritméticas. Esto último implica no sólo una nueva ironía, sino además una enorme tranquilidad para el lector quien no se ve obligado a aceptar la hiperbólica aberración. Quizás podamos incorporar -esto en un terreno de mágica suposición-, la eventualidad de un loro afrancesado y con cultura grecorromana; pero de ahí, asumir que también sea capaz de sumar, restar...

El narrador nos ahorra tal ejercicio de nuestra imaginación.

Ahora bien, cuando el médico trajo de Europa el primer fonógrafo de bocina, le hacía oir al loro las canciones de moda hasta que éste llegó a aprenderlas de memoria. Las cantaba con voz de mujer, si eran las de ella, y con voz de tenor si eran las de él, y terminaba con unas carcajadas libertinas que eran el espejo magistral de las que soltaban las sirvientas cuando lo oían cantar en francés (EATC: 29).

La literatura se nutre de hechos verosímiles fundamentalmente, es decir, de aquellas acciones que se revisten con apariencia de verdad. Ciertamente, este loro produce la risa en el lector y esas "carcajadas libertinas" -que eran el remate y conclusión para las canciones repetidas por él-, conllevan el sabor especial de lo inédito; parecen ser la reafirmación de lo insólito en el marco de esa misma irrealidad.

Los acontecimientos de esta primera parte de la novela se narran en tempo lento. No parece tener ninguna prisa el narrador por apresurarse mayormente en lo que está contando. Los hechos se suceden sin mayor violencia semántica: la muerte de Jeremiah, los preparativos para el entierro, el paseo por barrios de la ciudad, la llegada a casa de la amante del suicida, el diálogo con ella, regreso al hogar, la metadiégesis del loro circunscrita en otra metadiégesis que narra la forma en que el 
animal fue traído a la casa, costumbres del doctor Urbino, problemas de los "amores domesticados", desavenencias conyugales... En fin, numerosas situaciones interconectadas en el universo narrativo de esta novela y que nos conducen gradualmente hasta la muerte del doctor, la cual acontece ese mismo día.

\section{La muerte de Juvenal Urbino}

Las cosas suceden de una manera extraña en ese domingo de Pentecostés; Juvenal Urbino presiente algo; presiente su propia muerte como antes había olfateado, en el olor de las almendras amargas, el destino de los amores contrariados. Lo despertó la tristeza. No la que había sentido en la mañana ante el cadáver del amigo, sino la niebla invisible que le saturaba el alma después de la siesta, y que él interpretaba como una notificación divina de que estaba viviendo sus últimos atardeceres. Hasta los cincuenta años no había sido consciente del tamaño y el peso y el estado de sus vísceras. Poco a poco, mientras yacía con los ojos cerrados después de la siesta diaria, había ido sintiéndolas dentro, una a una, sintiendo hasta la forma de su corazón insomne, su higado misterioso, su páncreas hermético, y había ido descubriendo que hasta las personas más viejas eran menores que él, y que había terminado por ser el único sobreviviente de los legendarios retratos de grupo de su generación (EATC: 50).

El lenguaje narrativo se llena de poesía para describir el valor y la significación de esa tristeza en el despertar de la siesta. No puede menos que recordar al amigo muerto, pero en seguida diferencia ambos estados de ánimo: ante el cadáver del amigo lo había invadido la noción de impotencia y el profundo sentido de una muerte sin mayor explicación; ahora lo domina la sensación de misterio, esa metafórica niebla invisible que le saturaba el alma después de la siesta y que sólo podía ser interpretada como un aviso de Dios relativo a la culminación de su plazo de vida. Se siente viejo y angustiado. Se ve como sobreviviente único de los legendarios retratos. Esto representa la sensación de abandono y miseria ante la muerte cercana.

Agrega en seguida:

Cuando se dio cuenta de sus primeros olvidos, apeló a un recurso que le había oído a uno de sus maestros en la Escuela de Medicina: El que no tiene memoria se hace una de papel. Sin embargo, fue una ilusión efímera, pues habia llegado al extremo de olvidar lo que querían decir las notas recordatorias que se metía en los bolsillos, recorría la casa buscando los lentes que tenía puestos, volvía a darle vueltas a la llave después de haber cerrado las puertas, y perdía el hilo de la lectura porque olvidaba las premisas de los argumentos o la filiación de los personajes. Pero lo que más le inquietaba era la desconfianza que tenía en su propia razón: poco a poco, en un naufragio ineluctable, sentía que iba perdiendo el sentido de la justicia (EATC: 50). 
Nuevamente insiste el narrador en los factores lúdicos. Ese hombre ha debido luchar contra la pérdida de la memoria, pero todo ha sido inútil porque ese "naufragio ineluctable" lo lleva al extremo de no saber diferenciar ni siquiera cuestiones morales.

También complementa sus reflexiones al decir:

Por pura experiencia, aunque sin fundamento cientifico, el doctor Juvenal Urbino sabía que la mayoría de las enfermedades mortales tenían un olor propio, pero ninguno era tan específico como el de la vejez. Lo percibía en los cadáveres abiertos en canal en la mesa de disección, lo reconocía hasta en los pacientes que mejor disimulaban la edad, y en el sudor de su propia ropa y en la respiración inerme de su esposa dormida. De no ser lo que era en esencia, un cristiano a la antigua, tal vez hubiera estado de acuerdo con Jeremiah de Saint Amour en que la vejez era un estado indecente que debía impedirse a tiempo. El único consuelo, aun para alguien como él que había sido un buen hombre de cama, era la extinción lenta y piadosa del apetito venéreo: la paz sexual. A los ochenta y un años tenía bastante lucidez para darse cuenta de que estaba prendido a este mundo por unas hilachas tenues que podian romperse sin dolor con un simple cambio de posición durante el sueño, y si hacía lo posible para mantenerlas era por el terror de no encontrar a Dios en la oscuridad de la muerte (EATC: 50).

Retoma así el tema del suicidio como una salida para el dolor de la existencia y se autocontesta al señalar que él también hubiera optado por el suicidio a no ser por su condición de cristiano viejo.

Podemos observar casi inmediatamente cómo muere el anciano doctor al tratar de bajar al loro del árbol del mango.

El doctor Urbino agarró al loro por el cuello con un suspiro de triunfo: ca y est. Pero lo soltó de inmediato, porque la escalera resbaló bajo sus pies y él se quedó un instante suspendido en el aire, y entonces alcanzó a darse cuenta de que se había muerto sin comunión, sin tiempo para arrepentirse de nada ni despedirse de nadie, a las cuatro y siete minutos de la tarde del domingo de Pentecostés (EATC: 52-53).

Ha llegado el momento doloroso. Es el segundo deceso en el devenir de la novela. Curiosamente el tiempo se vuelve estático, queda como congelado para que el anciano se haga cargo de lo que está pasando realmente. Es el instante último de la vida en el cual el ser humano repasa raudamente lo que ha sido su existencia. Juvenal entiende -con esa lucidez que sólo da la inminencia de la muerte-, que se va para siempre sin haberse arrepentido, sin haberse despedido. Un detalle curioso consiste en señalar con absoluta precisión la hora exacta en que se dan los hechos; el narrador quiere hacer tan verosímil 
los acontecimientos que ni siquiera escapa a sus consideraciones la mencionada minucia.

La reacción de su esposa no se hace esperar:

Fermina Daza estaba en la cocina probando la sopa para la cena, cuando oyó el grito de horror de Digna Pardo y el alboroto de la servidumbre de la casa y enseguida el del vecindario. Tiró la cuchara de probar y trató de correr como pudo con el peso invencible de su edad, gritando como una loca sin saber todavía lo que pasaba bajo las frondas del mango, y el corazón le saltó en astillas cuando vio a su hombre tendido bocarriba en el lodo, ya muerto en vida, pero resistiéndose todavía un último minuto al coletazo final de la muerte para que ella tuviera tiempo de llegar. Alcanzó a reconocerla en el tumulto a través de las lágrimas del dolor irrepetible de morirse sin ella, y la miró por última vez para siempre jamás con los ojos más luminosos, más tristes y más agradecidos que ella no le vio nunca en medio siglo de vida en común, y alcanzó a decirle con el último aliento: -Sólo Dios sabe cuánto te quise (EATC: 53).

Es en este preciso momento en donde la carga emotiva del relato se torna más intensa. Los contrastes cobran una significación profunda. La anciana corre a pesar del peso de su edad. Corre y realmente al comienzo no sabe por qué. El lenguaje figurado expresa con desgarradora locura el sentimiento del momento; ese corazón que salta en astillas es la imagen hiperbólica del dolor inmenso de perder al hombre que fuera su compañía y apoyo en la existencia.

Estéticamente es muy bella la descripción de esta muerte. Se trata de dos seres que se amaron a pesar de muchos momentos de desencuentro amoroso. Se trata también de la antítesis de la novela, es decir, de los amores domesticados como les llama la voz que cuenta, de los amores realizados, como les hemos dado en denominar en este trabajo.

Parece como si la muerte revistiera de dignidad las acciones del hombre y en el momento de fenecer todo se suavizara y cambiase. Fermina se despide así de su esposo. A continuación y procediendo con base en firme contraste, el narrador prefiere abandonar el clímax alcanzado diciendo:

Fue una muerte memorable, y no sin razón. Apenas terminados sus estudios de especialización en Francia, el doctor Juvenal Urbino se dio a conocer en el país por haber conjurado a tiempo, con métodos novedosos y drásticos la última epidemia de cólera morbo que padeció la provincia (EATC: 53). 


\section{Conclusiones}

Finalmente, los diversos motivos que fueron considerados en el presente ensayo se relacionan íntimamente no sólo en este trabajo, sino también en la totalidad de la novela.

En primera instancia -y luego del planteamiento inicial en el que someramente se comparan los comienzos de las novelas de 1967 y 1985-, hemos presentado una breve relación comparatística en lo que refiere al valor y significación de las asociaciones literarias en tres contextos diferentes: García Márquez en El amor en los tiempos del cólera; Honoré de Balzac en Eugenia Grandet y Marcel Proust en A la búsqueda del tiempo perdido. En los tres casos aludimos a la importancia de los datos sinestésicos de diferente alcance, que allí aparecen, y marcamos también la conexión existente entre ellos.

En segundo lugar, la muerte está presentada como una fuerza fatal que ya había sido anunciada explícita e implícitamente en los casos analizados: en lo que refiere a Jeremiah de Saint-Amour el acontecimiento está explícito, él había preparado este suicidio para huir así del horror de la vejez - pero no por preparado deja de ser menos trágico; con Juvenal Urbino acontece algo semejante cuando al asistir a la conmemoración de los cincuenta años del médico Plácides Olivella, se asume -según lo comenta Grinor Rojo, autor ya citado en esta crítica-, que implícitamente se le está haciendo una despedida al veterano doctor quien va a ser sustituido, en el libre juego de la existencia, por el médico festejado; por ende sólo le resta a Juvenal Urbino dejar de existir, desaparecer de la escena.

En un tercer momento, nos detuvimos en el análisis de un tema que conlleva un ineludible carácter metafísico; a partir del instante en el cual el anciano doctor define a Jeremiah como un "santo ateo" para concluir que éstos son "asuntos de Dios", nos encontramos ante una concepción particular de la divinidad, casi podríamos hablar de un "dios garciamarquiano" que no responde a imperativos categóricos, sino a un concepto libre dictado por la conciencia individual del hombre.

En un cuarto apartado, el tema de los amores contrariados lo ofrecemos en el marco de un nuevo contraste entre ellos y los amores realizados o domésticos -véase en relación con este último aspecto los casos de Florentino y Fermina y de Juvenal y Fermina-; en un sentido diferente, pero en el mismo encuadre del tema trabajado, surge la 
relación entre los amores inútilmente contrariados de Jeremiah y su pareja, y el amor a la muerte como una forma de curación para la enfermedad de la vida, que profesa y pone en práctica el inválido de guerra.

Hemos analizado como penúltimo motivo aquel que refiere a la comicidad y ludismo del narrador cuando presenta y describe al loro de Paramaribo. Este loro que acompañó en momentos de tanta alegría al personaje, estará con él también en el instante trascendente de su propia muerte.

Por ello -y para terminar el ensayo- comentamos la muerte del anciano doctor cuando intenta atrapar al loro fugitivo.

Email: qluis@toluca.podernet.com.mx

\section{Bibliografía}

Abbagnano, Nicola (1989), Diccionario de filosofía, trad. de Alfredo N. Galletti, México: FCE.

Amado, Jorge (1991), "Dos palabras sobre Gabo", en Homenaje a Gabriel García Márquez, selección y prólogo de Juan Gustavo Cobo Borda, Bogotá: Siglo del Hombre Editores.

Balzac, Honoré de (1990), Eugenia Grandet, Barcelona: Equipo Editorial.

García Márquez, Gabriel (1990), Cien años de soledad, México: Diana.

(1990), El amor en los tiempos del cólera, México: Diana.

(1990), Del amor y otros demonios, México: Diana.

Grinor, Rojo (1991), "El amor, la vejez y la muerte en los tiempos del cólera", en Homenaje a Gabriel García Márquez, selección y prólogo de Juan Gustavo Cobo Borda, Bogotá: Siglo del Hombre Editores.

Proust, Marcel (1985), A la búsqueda del tiempo perdido, trad. Julio Gómez de la Serna, Madrid: SARPE. 